\title{
The Prevalence and Characteristics of Psoriatic Arthritis in Patients With Psoriasis in a Tertiary Hospital
}

\author{
Nilay ÇINAR, ${ }^{1}$ Hatice BODUR,, Filiz ESER, ${ }^{1}$ Ülker GÜL, ${ }^{2}$ Müzeyyen GÖNÜL,${ }^{2}$ Işıl Deniz OĞUZ ${ }^{2}$ \\ ${ }^{1}$ Department of Physical Medicine and Rehabilitation, Ankara Numune Training and Research Hospital, Ankara, Turkey \\ ${ }^{2}$ Department of Dermatology, Ankara Numune Training and Research Hospital, Ankara, Turkey
}

\begin{abstract}
Objectives: This study aims to investigate psoriatic arthritis (PsA) prevalence in patients with psoriasis (Ps), and compare clinical and laboratory characteristics of patients with or without PsA.

Patients and methods: A total of 126 patients (59 males, 67 females; mean age $45.6 \pm 13.8$ years; range 18 to 82 years) with Ps who applied to Dermatology Outpatient Clinic between October 2009 and September 2010 were included in this study. The patients were screened for PsA using Classification of Psoriatic Arthritis criteria. The patients classified as PsA were grouped according to Moll and Wright criteria. Enthesopathy was evaluated according to Maastricht Ankylosing Spondylitis Enthesis score. Psoriasis Area and Severity Index scores were calculated by the same dermatologist.

Results: The prevalence of PsA was $25.4 \%$. Ps duration was significantly longer in the group with PsA. The most common type was asymmetrical oligoarticular type (53.1\%). Compared to previous studies, the rate of isolated spondyloarthropahty was higher in our study (21.9\%). Nail involvement Psoriasis Area and Severity Index score, mean erythrocyte sedimentation rate, and C-reactive protein values were significantly higher in the group with PsA.

Conclusion: High rate of isolated spondyloarthropahty in patients with PsA indicates that PsA must be kept in mind in the differential diagnosis of seronegative spondyloarthropathies. The fact that nail involvement is seen more frequently in patients with arthritis may assist in screening of PsA in patients with Ps. In addition, our results showing a higher probability of PsA development in patients with more severe skin lesions and a higher probability of arthritis development in patients with long lasting Ps may guide clinicians in terms of the probability of arthritis development in patients with Ps.

Keywords: Prevalence; psoriasis; psoriatic arthritis.
\end{abstract}

Psoriatic arthritis (PsA) is a chronic inflammatory disorder which develops in association with psoriasis in which rheumatoid factor (RF) is usually negative and there are no rheumatoid nodules. It is classified within the group of seronegative spondyloarthropathies. ${ }^{1,2}$ Since PsA does not have a widely accepted classification and diagnostic criteria, it is hard to estimate its prevalence. ${ }^{3}$ Classification of Psoriatic Arthritis (CASPAR) criteria was published in 2006. ${ }^{1}$ To our knowledge, there are only a few prevalence or incidence studies which used CASPAR criteria in relevant English literature. ${ }^{4-6}$ In this study, we aimed to investigate PsA prevalence in patients with psoriasis, and clinical and laboratory characteristics of the patients.

\section{PATIENTS AND METHODS}

A total of 126 patients (59 males, 67 females; mean age $45.6 \pm 13.8$ years; range 18 to 82 years) with psoriasis and older than 18 years of age who were admitted to Dermatology Outpatient Clinic of Ankara Numune Training and Research Hospital between October 2009 and September 
2010 were included. The protocol of this study was approved by the Local Ethic Committee of Ankara Numune Training and Research Hospital. All of the participants were informed about treatment procedure and their signed informed consents were obtained. Patients were screened for PsA using CASPAR criteria. ${ }^{7}$ The patients were also evaluated by a physiatrist of our clinic. Age, gender, psoriasis duration and arthritis duration of the patients as well as nail involvement and presence of dactylitis were noted. Peripheral joints and spine of the patients were examined in detail. Examination of 13 sensitive points was performed to diagnose enthesopathy according to Maastricht Ankylosing Spondylitis Enthesis Score. ${ }^{8}$ PsA patients were grouped into five subtypes according to Moll and Wright criteria. ${ }^{2}$ The Psoriasis Area and Severity Index (PASI) scores of the patients were calculated by the same dermatologist. ${ }^{9,10}$ The patients were grouped according to their PASI scores as follows: $<3$ : mild; 3-15: moderate; and $>15$ : severe psoriasis. Blood samples were obtained from all patients to measure erythrocyte sedimentation rate (ESR), C-reactive protein (CRP), and RF using turbidimetric method. In those patients with inflammatory back pain, radiological assessments including X-ray or magnetic resonance imaging of sacroiliac joints were performed.

\section{Statistical analysis}

The statistical analysis of data was performed using SPSS for Windows version 11.5 package program (SPSS Inc., Chicago, IL, USA). The normality of continuous variables was analyzed using Shapiro Wilk test. The descriptive statistics were presented as mean \pm standard deviation or median [minimum (min.)-maximum (max.)] for continuous variables, and as the number of the cases and (\%) for categorical variables. The significance of difference between the means of the groups was investigated using Student's t test while the significance of the difference between the medians was investigated using Mann-Whitney $\mathrm{U}$ test. Categorical variables were analyzed using Pearson's Chi-square test. $\mathrm{P}<0.05$ was considered as statistically significant.

\section{RESULTS}

Thirty-two patients (25.4\%) had PsA according to CASPAR classification criteria. ${ }^{1}$ The demographic characteristics of the patients are summarized in Table 1. The duration of psoriasis was longer in arthritis $(+)$ group $(p<0.05)$.

The onset time of psoriasis and PsA were investigated. Arthritis and psoriasis which started within one year was regarded as simultaneous onset. Arthritis started before psoriatic lesions in three $(9.4 \%)$ of 32 patients, simultaneously with psoriasis in one patient (3.1\%), and after psoriatic skin lesions in 28 patients (87.5\%).

According to Moll and Wright criteria, some patients with PsA were included in more than one subgroup (Table 2). Most common types were asymmetrical oligoarticular type (53.1\%) and spondylitis type (43.8\%). There was no difference with respect to gender when 14 patients ( 8 males, 6 females) with spondylitis were compared to 18 patients (10 males, 8 females) without spondylitis $(p>0.05)$. Sacroiliitis was detected in 12 patients (37.5\%). Sacroiliitis was detected with anteroposterior pelvic X-ray in six patients (50\%) and magnetic resonance imaging in the other six patients (50\%). Dactylitis was detected in seven patients (21.9\%) and enthesopathy in 20 patients

\begin{tabular}{|c|c|c|c|c|c|}
\hline & \multicolumn{2}{|c|}{ Arthritis (-) group $(\mathrm{n}=94)$} & \multicolumn{2}{|c|}{ Arthritis $(+)$ group $(n=32)$} & \multirow[b]{2}{*}{$p$} \\
\hline & $\mathrm{n}$ & Mean \pm SD & $\mathrm{n}$ & Mean \pm SD & \\
\hline Age & & $45.9 \pm 14.1$ & & $44.8 \pm 13.2$ & 0.688 \\
\hline Gender & & & & & 0.216 \\
\hline Female & 53 & & 14 & & \\
\hline Male & 41 & & 18 & & \\
\hline Duration of psoriasis (months) & & $121.9 \pm 97.7$ & & $205.4 \pm 199.4$ & 0.046 \\
\hline PsA duration of psoriasis (months) & - & & & $51 \pm 76.2$ & - \\
\hline Onset age of PsA & - & & & $40.5 \pm 12.3$ & - \\
\hline
\end{tabular}


Table 2. Distribution of patients with psoriatic arthritis according to Moll and Wright criteria

\begin{tabular}{lcc}
\hline Types & $\mathrm{n}$ & $\%$ \\
\hline Spondylitis & 7 & 21.9 \\
Distal interphalangeal joint involvement & 2 & 6.3 \\
Asymmetrical oligoarthritis & 11 & 34.4 \\
Symmetrical polyarthritis & 4 & 12.5 \\
Arthritis mutilans & 1 & 3.1 \\
Spondylitis and asymmetrical oligoarthritis & 6 & 18.8 \\
Spondylitis and arthritis mutilans & 1 & 3.1 \\
Total & 32 & 100.0 \\
\hline
\end{tabular}

(62.5\%). The mean Maastricht Ankylosing Spondylitis Enthesis score was 6.4 \pm 2.2 .

There were 65 patients (51.6\%) with nail involvement. While $42(44.7 \%)$ of these patients were in arthritis (-) group, $23(71.9 \%)$ were in arthritis $(+)$ group $(p<0.01)$ (Table 3). Laboratory results revealed that ESR and CRP levels were higher in arthritis (+) group than in arthritis (-) group (both $\mathrm{p}$ values $<0.01$ ).

The mean PASI score was higher in arthritis $(+)$ group than in arthritis $(-)$ group $(p<0.05)$. No statistically significant difference was detected when the groups were compared according to the severity of the PASI scores (Table 3).

\section{DISCUSSION}

In several studies the prevalence of PsA in patients with psoriasis was $42 \%$ with Moll and Wright criteria, ${ }^{11} 7.7 \%{ }^{12}$ and $9.1 \%{ }^{13}$ with European Spondylarthropathy Study Group classification criteria, and $13.8 \%$ with CASPAR. ${ }^{4}$ Maldonado
Ficco et al. ${ }^{6}$ reported the prevalence of PsA according to CASPAR criteria, Assessment of SpondyloArthritis International Society peripheral and axial spondyloarthropahty criteria, and New York criteria for ankylosing spondylitis. The first 100 patients consecutively attending a psoriasis dermatology clinic were assessed. Seventeen patients had peripheral arthritis as follows: nine mono/oligoarticular and eight polyarthritis. Seventeen percent of patients fulfilled CASPAR and Assessment of SpondyloArthritis International Society peripheral criteria, 6\% New York, and 5\% Assessment of Spondylo Arthritis International Society axial criteria. Kumar et al. ${ }^{5}$ reported the prevalence of PsA according to CASPAR criteria as $8.7 \%$ in 1,149 psoriasis patients. Various prevalence in the literature may be related to the number of the patients included in the studies and the differences of the classification criteria employed in the diagnosis of PsA. For instance, a study using Moll and Wright criteria ${ }^{11}$ showed higher prevalence. This may be associated with regional difference or classification criteria. In addition, the differences in the patient populations included in the studies may play role on the outcomes. For example, studies including patients with severe symptoms reported high prevalence.

There are conflicting results about the relationship of psoriasis duration and development of PsA. Wilson et al. ${ }^{14}$ reported that calendar year was not related to risk of PsA development. On the other hand, Gladman et al. ${ }^{15}$ reported that development of deforming arthritis such as arthritis multilans was related with early onset of psoriasis. In our study, we found that duration of psoriasis was significantly longer in arthritis (+)

Table 3. Nail involvement, Psoriasis Area and Severity Index scores and laboratory results of patients with or without arthritis

\begin{tabular}{|c|c|c|c|c|c|c|c|c|c|}
\hline & $\mathrm{n}$ & $\%$ & Median & Min.-Max. & $\mathrm{n}$ & $\%$ & Median & Min.-Max. & $p$ \\
\hline Nail involvement & 42 & 44.7 & & & 23 & 71.9 & & & 0.008 \\
\hline Psoriasis Area and Severity Index & & & 2.8 & $0.3-30.0$ & & & 3.6 & 0.8-37.7 & 0.032 \\
\hline Psoriasis Area and Severity Index grade & & & & & & & & & 0.125 \\
\hline Mild & 56 & 59.6 & & & 13 & 40.6 & & & \\
\hline Moderate & 31 & 33.0 & & & 17 & 53.1 & & & \\
\hline Severe & 7 & 7.4 & & & 2 & 6.3 & & & \\
\hline Erythrocyte sedimentation rate $(\mathrm{mm} / \mathrm{h})$ & & & 16.5 & $1-94$ & & & 21.5 & $10-85$ & $<0.01$ \\
\hline C-reactive protein $(\mathrm{mg} / \mathrm{dL})$ & 0.5 & $0.2-13.4$ & & & & & 0.8 & $0.5-20$ & $<0.01$ \\
\hline
\end{tabular}


group and the probability of PsA development was higher in patients with long lasting psoriasis.

Although some studies indicate that males and females were affected equally by PsA, ${ }^{4,13}$ some series report a female predominance ${ }^{12}$ while others report a male predominance. ${ }^{15}$ In our series, the frequency of arthritis was higher in males, although not statistically significant.

Our classification of PsA according to Moll and Wright criteria revealed that the oligoarticular type was more common ${ }^{2,16,17}$ whereas other studies demonstrated that polyarticular type was the most common, ${ }^{15}$ or found similar prevalence for oligoarthritis and polyarthritis. ${ }^{18}$

We detected spondylitis in $43.8 \%$ and isolated spondylitis in $21.9 \%$ of the patients. These ratios were higher than the ones previously reported in the literature. The spondylitis of PsA is uncommon as a predominant feature, and accounts for only approximately $5 \%$ of the cases. ${ }^{19}$ However, spondylitis was reported as $20-40 \%$ in patients with PsA after careful clinical and radiological assessments. ${ }^{19}$ Dactylitis is an important finding of PsA and is reported in between $12-48 \%$ of the patients. ${ }^{20-22}$ In our study, we noted dactylitis in $22 \%$ of the patients.

Enthesitis is another important finding of PsA. Some investigators have emphasized that enthesitis is the primary finding of PsA. ${ }^{4,13,23}$ Plantar fascia and the insertion point of Achilles tendon to the heel are the most frequently involved sites. ${ }^{24}$ Ibrahim et al. ${ }^{4}$ detected enthesitis in $83.3 \%$ of their patients while another study from $\operatorname{Iran}^{13}$ reported this value as $20.7 \%$. We found enthesitis in $62.5 \%$ of patients with PsA, and enthesopathy was frequently seen in Achilles tendon.

Psoriasis Area and Severity Index is a widely accepted psoriasis evaluation index used as an outcome measure. ${ }^{10}$ Although some studies indicated more severe skin lesions in patients with PsA, ${ }^{13}$ other studies reported lesions and joint involvement. ${ }^{23}$ We detected significantly higher mean PASI scores in patients with PsA.

Nail involvement is more common in patients with PsA and is an important finding that supports diagnosis of PsA. ${ }^{25}$ While nail involvement is observed in $40-49 \%$ of psoriasis patients, it is seen in $57-97 \%$ of patients with PsA. ${ }^{3,11,13,22}$ Nail involvement is common in patients with distal interphalangeal joint involvement. ${ }^{2,9,25}$ In our study, we detected nail involvement to be $44.7 \%$ in arthritis (-) group and $71.9 \%$ in arthritis (+) group. All patients with distal interphalangeal joint involvement had nail involvement as well.

High ESR and CRP are among the most characteristic laboratory abnormalities in patients with PsA. ${ }^{21,26,27}$ In our study, we also detected significantly higher ESR and CRP levels in the group with PsA. Although patients with PsA are typically seronegative for $R F$, in a study $R F$ was positive in $5-9 \%$ of the patients. ${ }^{26}$ We did not find RF positivity in any of our PsA patients.

In conclusion, the prevalence of PsA was determined as $25.4 \%$ in our study. According to Moll and Wright criteria, the most common type was asymmetrical oligoarticular type. Higher isolated spondylitis rate $(22 \%)$ in our patients with PsA indicates that PsA must be kept in mind in the differential diagnosis of spondylitis, particularly ankylosing spondylitis. In addition, longer duration of psoriasis, and more common nail involvement and severe skin lesions in psoriasis may guide the clinician for the probability of PsA development in these patients.

\section{Declaration of conflicting interests}

The authors declared no conflicts of interest with respect to the authorship and/or publication of this article.

\section{Funding}

The authors received no financial support for the research and/or authorship of this article.

\section{REFERENCES}

1. Turkiewicz MA, Moreland LW. Psoriatic Arthritis: Current concept on pathogenesis oriented therapeutic options. Arthritis Rheum 2007;56:1051-66.

2. Moll JM, Wright V. Psoriatic arthritis. Semin Arthritis Rheum 1973;3:55-78.

3. Gladman DD, Antoni C, Mease P, Clegg DO, Nash P. Psoriatic arthritis: epidemiology, clinical features, course and outcome. Ann Rheum Dis 2005;64:14-7.

4. Ibrahim G, Waxman R, Helliwell PS. The Prevalence of PsA in people with Ps. Arth and Rheum 2009;61:373-8.

5. Kumar R, Sharma A, Dogra S. Prevalence and clinical patterns of psoriatic arthritis in Indian patients with psoriasis. Indian Journal of Dermatology, Veneral and 
Leprology 2014;80:15-23.

6. Maldonado Ficco H, Citera G, Maldonado Cocco JA. Prevalence of psoriatic arthritis in psoriasis patients according to newer classification criteria. Clin Rheumatol 2014;33:243-6.

7. Taylor W, Gladman DD, Helliwell P, Marchesoni $\mathrm{A}$, Mease $\mathrm{P}$, Mielants $\mathrm{H}$ and the CASPAR Study Group. Classification criteria for psoriatic arthritis: development of new criteria from a large international study. Arthritis Rheum 2006;54:2665-73.

8. Heuft-Dorenbosch L, Spoorenberg A, Van Tubergen A et al. Assessment of enthesis in AS. Ann Rheum Dis 2003;62:127-32.

9. Fredriksson T, Pettersson U. Severe psorasis: oral therapy with new retinoid. Dermatologica 1978;157:238-44.

10. Berth-Jones J, Grotzinger K, Rainville C, Pham B, Huang J, Daly S, et al. A study examining inter- and intrarater reliability of three scales for measuring severity of psoriasis: Psoriasis Area and Severity Index, Physician's Global Assessment and Lattice System Physician's Global Assessment. Br J Dermatol 2006;155:707-13.

11. Green L, Meyers OL, Gordon W, Briggs B. Arthritis in psoriasis. Ann Rheum Dis 1981;40:366-9.

12. Gisondi P, Girolomoni G, Sampogna F, Tabolli S, Abeni D. Prevalence of psoriatic arthritis and joint complaints in a large population of Italian patients hospitalised for psoriasis. Eur J Dermatol 2005;15:279-83.

13. Jamshidi F, Bouzari N, Seirafi H, Farnaghi F, Firooz A. The Prevalence of PsA 243 in Ps patients in Tehran, Iran. Arch Iranian Med 2008;11:162-5.

14. Wilson FC, Icen M, Crowson CS, McEvoy MT, Gabriel $\mathrm{SE}$, Kremers HM. Incidence and clinical predictors of psoriatic arthritis in patients with psoriasis: a populationbased study. Arthritis Rheum 2009;61:233-9.

15. Gladman DD, Shuckett R, Russell ML, Thorne JC, Schachter RK. Psoriatic arthritis - an analysis of 220 patients. Q J Med 1987;62:127-41.
16. Kammer GM, Soter NA, Gibson DJ, Schur PH. Psoriatic arthritis: a clinical, immunologic and HLA study of 100 patients. Semin Arthritis Rheum 1979;9:75-97.

17. Veale D, Rogers S, Fitzgerald O. Classification of clinical subsets in psoriatic arthritis. $\mathrm{Br} J 253$ Rheumatol 1994;33:133-8.

18. Torre-Alonso JC, Rodriguez Perez A, Arribas Castrillo JM, Balina Garcia J, Riestra Noriega JL, Lopez Larrea C. Psoriatic arthritis: a clinical, immunological and radiological study of 180 patients. Br J Rheumatol 199;30:245-50.

19. Bruce IN. Psoriatic arthritis: clinical features. In: Hochbeg MC, Silman JS, Smolen ME, Weinblatt M, editors: Rheumatology. 4th ed. Philedelphia: Mosby; 2008. p. 1165-75.

20. Brocbank JE, Stein M, Schentg CT, Gladman DD. Dactylitis in psoriatic arhritis: a marker for disease severity? Ann Rheum Dis 2005;64:188-90.

21. Moghaddassi M, Shahram F, Chams-Davatchi C, Najafizadeh SR, Davatchi Z. Different aspects of PsA: Analysis of 150 Iranian patients. Arch Iranian Med 2009;12:279-83.

22. Gunal EK, Kamali S, Gul A, Ocal L, Konice M, Aral O, et al. Clinical evaluation and comparison of different criteria for classification in Turkish patients with psoriatic arthritis. Rheumatol Int 2008;28:959-64.

23. Gladman DD. Psoriatic arthritis. Dermatologic Therapy 2004; 17:350-63.

24. Gladman DD, Chandran V. Clinical features of psoriatic arthritis. In: The Facts. 1st ed. Oxford University Press 2009. p. 33-45.

25. Krueger GG. Clinical features of psoriatic arthritis. Am J Manag Care 2002;8:160-70.

26. Mease P, Goffe BS. Diagnosis and treatment of psoriatic arthritis. J Am Acad Dermatol 2005;52:1-19.

27. Gladman DD, Farewell VT, Nadeau C. Clinical indicators of progression in 271 psoriatic arthritis: multivariate relative risk model. J Rheumatol 1995;22:675-9. 